\title{
A Casting Mould for Rapid Tube Hydroforming Prototyping
}

\author{
Andrzej Kochański $\oplus_{(\infty)}^{*}$, Hanna Sadłowska ${ }_{(\mathbb{C}}$ \\ Warsaw University of Technology, Faculty of Production Engineering, Narbutta 85, 02-524 Warsaw, Poland \\ *e-mail: akochans@wip.pw.edu.pl
}

(C) 2020 Authors. This is an open access publication, which can be used, distributed and reproduced in any medium according to the Creative Commons CC-BY 4.0 License requiring that the original work has been properly cited.

Received: 5 May 2020/Accepted: 30 June 2020/ Published online: 15 July 2020

This article is published with open access at AGH University of Science and Technology Press

\begin{abstract}
In recent years, hydroforming has clearly expanded its range of industrial applications due to the growing interest in products which combine high strength with low weight. A current limitation of this technology was its economically justified production volume since the costs of producing tools eliminates the possibility of using hydroforming technology in prototype and single part production. The paper presents a freshly patented solution that allows for single part hydroforming. The new technology combines traditional hydroforming machines with a new approach to tool production. The new rapid die is made quickly and cheaply. The use of materials known from the production of foundry moulds causes the die to deform during hydroforming, but it is a controlled deformation. Thanks to the use of numerical modelling, the deformation of the mould cavity is predicted and taken into account at the design stage. The article presents important issues that need to be considered in the design of this innovative process.
\end{abstract}

\section{Keywords:}

hydroforming, casting mould, rapid prototyping, process numerical modelling, hydroforming classification

\section{INTRODUCTION}

The growing interest in hydroforming as a method of component forming is tightly connected with increased demand to combine the high strength of components with their low weight. This is important in many areas of use, such as aerospace or automotive industries or in the production of bicycle components [1]. In recent years, the development of modern vehicle construction has led to an increase in the application of hydroforming processes in the production of lightweight automotive and aerospace components.

One of the limitations of hydroforming was the fact that the forming is in a short series. A consequence of the high die cost was that hydroforming was only economically justified for a series of 1,000 pieces. The introduction of plastic or even hardwood dies, which are cheaper and easier to prepare, made hydroforming economically justified for shorter series, even for series of 100 pieces [2]. However, the production of individual exemplars still remained economically unjustified.

Rapid changes in machines and devices under production, the necessity for prototyping, as well as individual demand have made it a matter of urgent necessity to develop a new technology which would employ hydroforming but which, at the same time, would make the use of a very cheap forming die possible. In order to reduce the die price to the minimum, dies need to be produced in a very simple way and with the use of common and cheap materials. The development of such a method, as shown in Figure 1, would allow the extension of the hydroforming variety for the entire range of serial sizes of manufactured components.

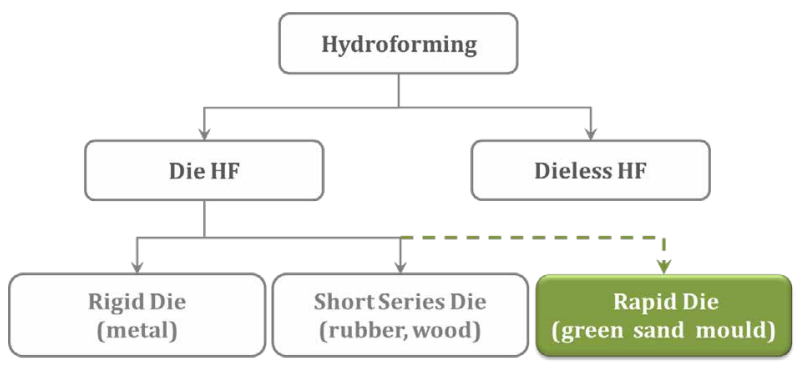

Fig. 1. Process classification according to the tools used in hydroforming

The present freshly patented method for metal tube hydroforming is dedicated to short product series or even single products and prototypes [3]. The method is applicable to forming difficult-to-machine materials. The well-known technique uses dies made of plastic or wood, especially to form short product series. The use of moulding sand and the properly prepared geometry of the casting mould makes it possible to shape materials at high temperatures, something which could not be done in previous short series solutions where a plastic or wooden die were used. 


\section{RAPID DIE HYDROFORMING TECHNOLOGY}

The requirements for cheap and easy-to-obtain materials that may be used in the preparation of prototype hydroforming dies are satisfied by foundry moulding sands, for instance by green sands or by moulding sands with water glass. As originally planned, materials used for foundry moulding sands are cheap, easy to obtain, and in the case of green sands, suitable for reuse. In the process of profile forming, a die made of moulding materials gives in to pressure and does not stick to the stable, unchanging shape of the die cavity. The main point of the proposed technological solution is to set the original shape of the die cavity in the function of the properties of the moulding sand used for the making of the die, as well as the properties of the profile under forming. The original shape of the die cavity is selected in numerical modelling.

Figure 2 schematically represents the forming mechanism proposed in the PL424401 patent [3]. The expanding profile in the die cavity increases its volume and thereby displaces the moulding sand which induce its quick local compacting. The moulding sand is compacted in places of contact with the profile, which inhibits and eventually stops the profile extension process. At the same time, the areas of the profile unsupported or partially supported by the mould undergoes free forming. The locking expansion in selected areas with the simultaneous free or semi-free shaping in other areas of moulding die enables to achieve the designed shape.

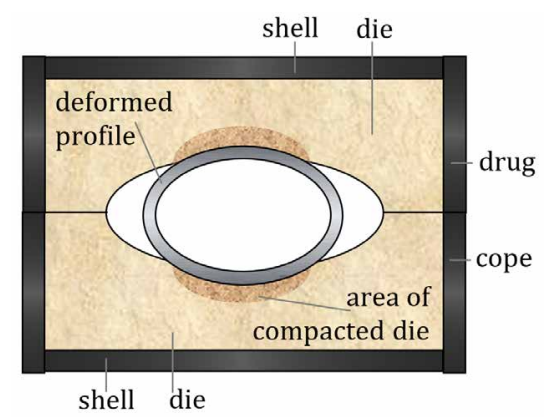

Fig. 2. A cross-section of the die together with the profile under forming - the schematic forming mechanism (based on the original patent [3])

The first step in developing the RTH technology based on the RTH method proposed in the patent was to build a numerical model aimed to investigate the influence of moulding sand properties on the tube deformation method in the new technological process. Such an approach seems to be convenient to estimate the outcome of and for controlling the process of deforming the moulding die which takes place during the profile expansion, as well as for establishing the ultimate shape of the profile. The profile shape depends on the properties of the material from which the profile is made, its original geometry, as well as the properties of the moulding sand from which the die has been made and the boundary conditions (for instance, the friction between the moulding sand and the profile under forming).
As has been demonstrated, for instance, in [4], it is the Mohr-Coulomb (M-C) material model which is commonly used for the initial calculations in the numerical modelling of moulding sands in the compacting process. For moulding sands and loose materials, the cohesion coefficient $c$ and the internal friction angle $\phi$, which are the critical values for the $\mathrm{M}-\mathrm{C}$ model, assume the values within the following ranges: $c=0.1-5.0 \mathrm{MPa}$, and $\phi=10^{\circ}-50^{\circ}$ [5]. Both parameters determine the internal resistance of the material related to tangential stress caused by normal pressure [6]. From a literature review on moulding sands, it emerges that a change of cohesion and internal friction angle makes it possible to exert a considerable influence on the way in which the profile is being formed. However, the authors of this article wanted to check the real impact of mass parameters on the deformability of tubes in RTH processes. The research provides for determining the impact of both moulding sand parameters ( $c$ and $\phi$ ) on the tube deformability in the RTH process. Therefore, a number of numerical experiments were performed using a variety of parameters $c$ and $\phi$ combinations using FEM simulations of RTH process of the example presented in the patent document. All of the examined combinations of cohesion $c$ and friction angle $\phi$ are shown in Table 1 . The symmetry of the moulding die-profile system was used and the quarter section was modelled to simplify and speed up the calculations. A geometric model of the Plane Strain type was used, in which 2D triangular elements and quadrangular 2D elements were used to generate the mesh covering the moulding die and tube respectively, see Figure 3. In the zone of initial contact between the mass and the tube, the mesh was compacted.

The mass was limited from the outside with rigid elements intended to simulate a moulding box which prevents the mass from moving outwards. Pressure was applied to the inner edges of the tube elements and the value pressure increased from $0 \mathrm{MPa}$ to $420 \mathrm{MPa}$. The simulation time was set at 5 seconds and divided into 100 equal increments.

Table 1

Numerical calculations cases in $c$ and $\phi$ analysis

\begin{tabular}{cccccc}
\hline $\begin{array}{c}\text { Cohesion } \boldsymbol{c} \\
{[\mathrm{MPa}]}\end{array}$ & $\mathbf{1 0}$ & $\mathbf{2 0}$ & $\mathbf{3 0}$ & $\mathbf{4 0}$ & $\mathbf{5 0}$ \\
\hline 0.1 & 1 & 2 & 3 & 4 & 5 \\
\hline 0.5 & 6 & 7 & 8 & 9 & 10 \\
\hline 1.0 & 11 & 12 & 13 & 14 & 15 \\
\hline 1.5 & 16 & 17 & 18 & 19 & 20 \\
\hline 5.0 & 21 & 22 & 23 & 24 & 25 \\
\hline
\end{tabular}

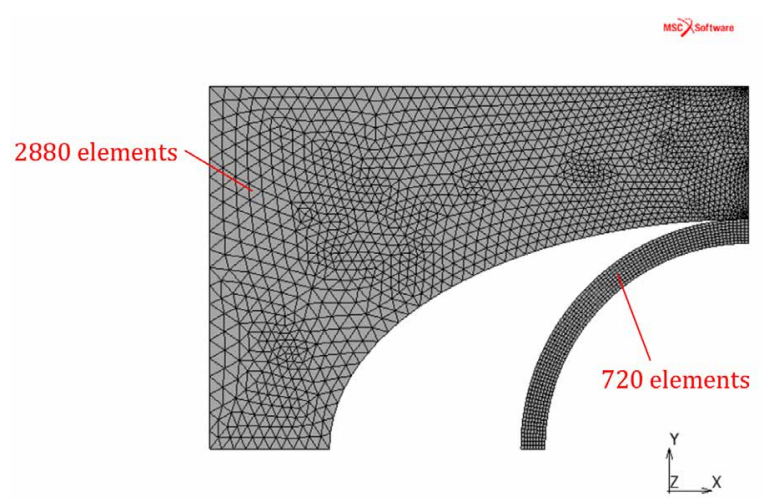

Fig. 3. A mesh in RTH numerical model 
Classic green sand (with bentonite) masses take values from $c=0.1$ and $\phi=10$ while high values of $c$ and $\phi$ e.g. 5 and 50, are characteristic for soils e.g. sand rocks [7]. Moulding sands with inorganic binders are characterized by lower parameters, not greater than $c=1.5$ and $\phi=40$. Such a significant $c$ and $\phi$ dispersion causes that masses with bentonite and masses with water glass binders will behave significantly differently during profile expansion. The numerical simulations results confirmed the clear difference in behaviour, as shown in the two extreme cases 1 and 19 of numerical modelling (both marked in grey in Table 1). These two distant range cases were selected to effectively illustrate the impact of cohesion and friction angle parameters. The case 1 refers to the low internal resistance $\left(c=0.1 \mathrm{MPa}\right.$, and $\left.\phi=10^{\circ}\right)$ and case 19 refers to the high internal resistance $\left(c=1.5 \mathrm{MPa}\right.$, and $\left.\phi=40^{\circ}\right)$.

The calculations of the results of the deformation of the die and the tube for 1 and 19 cases are presented in Figure 4 . The colours used in the pictures represent the displacement moulding sand of the die in the same process time and internal profile pressure load (420 MPa). The case 1 results (Fig. 4a) show considerably larger moulding sand displacement caused by the movement of the expanding profile. At the same time, a much larger deformation of the tube in the contact zone with the die can be observed than in the case of using a mass characterized by a much greater internal shear resistance, i.e. for case 19 shown in Figure 4 b.

a)

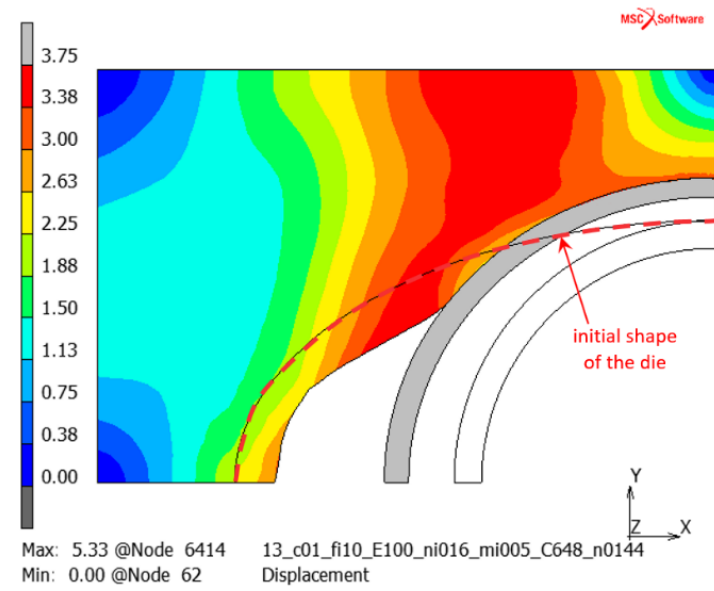

b)

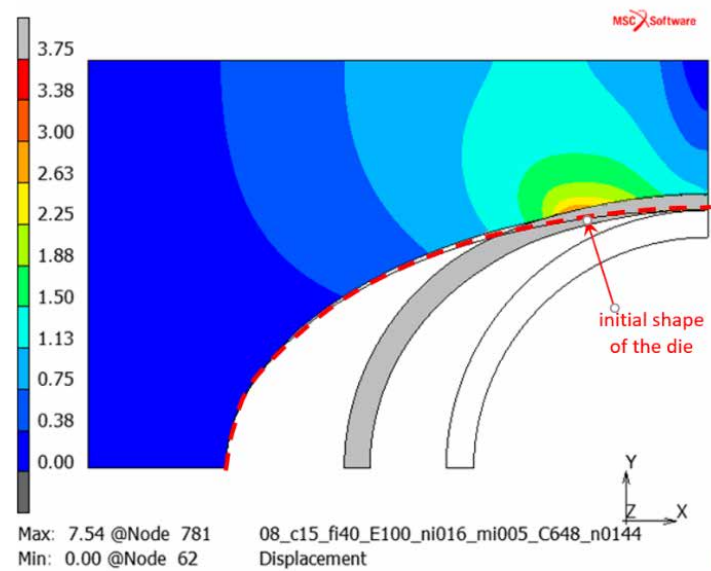

Fig. 4. Mass displacement (in millimetres) during profile hydroforming with an elliptical cross-section die cavity in two kinds of moulding sand properties: a) $c=0.1$ and $\phi=10^{\circ}$; b) $c=1.5, \phi=40^{\circ}$
From the comparison presented in Figure 4 one can also observe a significant difference in the deformation of the profile in the directions of the major and minor axes expressed in the proportion of the large axis and the small axis. For case 1 , the axes ratio is equal to 1.08 , while for case 19 it is 1.34. Furthermore it is worth noting the behaviour of the moulding sand during the forming process. The occurrence of mass compaction associated with tube expansion is easily discerned in the case of mass with $c$ and $\phi$ high values (Fig. 4b) where the outline of the moulding die cavity moves entirely over the initial shape of the die during the expansion process. This clearly indicates the reduction of the mass volume, i.e. the compaction of the mass. However, for mass with lower $\phi$ and $c$, two processes occur simultaneously: mass compaction and displacement into areas not supported by a hydroformed profile. The part of the moulding sand visible in Figure 4a moved below the initial shape and which indicates that only part of the mass has been compacted but some of it just displaced.

\section{METHODS AND MATERIALS}

Experimental studies were conducted with the use of the tube hydroforming measurement site (TH stand), designed and built at the Warsaw University of Technology hydroforming stand HF at the Department of Metal Forming and Foundry [8]. The TH stand allows both die and free tube hydroforming processes to be performed, thereby making it possible to obtain information about the material, as well as optimal process parameters [9] and makes useful to examine the new RTH method.

A methodology of RTH was developed to adjust and perform the first experiments on the TH stand and the special geometry of the die has been designed to put into practice the main idea of the RTH method.

The original shape of the die followed from the assumption that the profile under forming would be in contact with the moulding mass from the very beginning - thus, the original cavity diameter equalled the outside diameter of the profile under forming. However, it turned out that the friction force following from the moulding sand-profile friction coefficient is so big that it hinders the displacement of the profile material along the axis, thereby making impossible the feeding of the profile under forming in its thinned areas. A photo of the moulding die and the initial profile geometry are shown in Figure 5 and Figure 6, respectively.
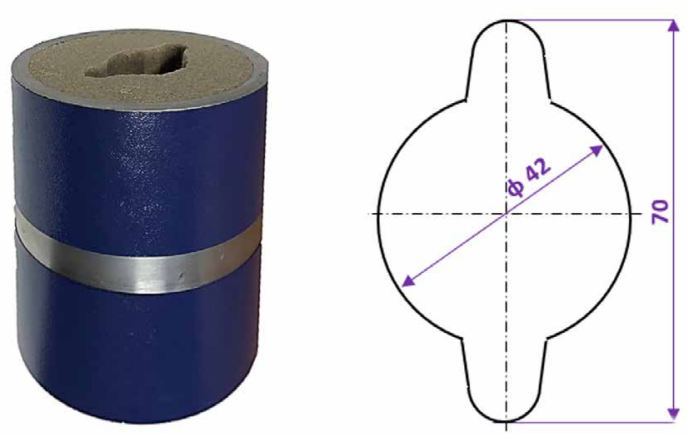

Fig. 5. A die made of moulding sand and the die cavity geometry 


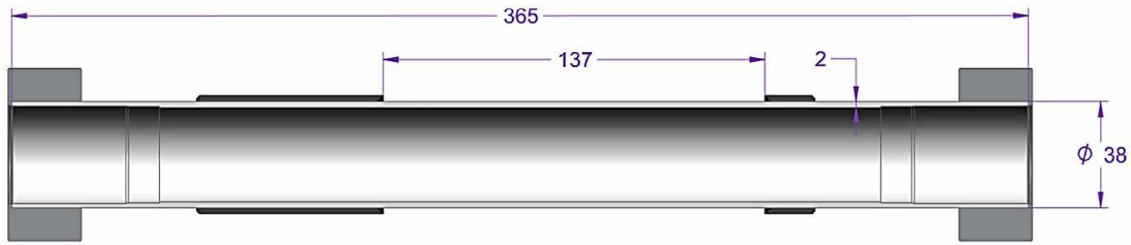

Fig. 6. The initial profile geometry - RTH tube specimen: outer dimension $\emptyset 38$; thickness of the wall 2 seamless tube (material: normalized steel E235)

In the initial experimental studies, moulding sand with water glass was used. The composition of the moulding sand is presented in Table 2 that also shows the relative percentages traditionally used to report the composition of the mass containing the binding material and the catalyst.

\section{Table 2}

The composition of the moulding sand with water glass

\begin{tabular}{ccc}
\hline $\begin{array}{c}\text { Moulding sand } \\
\text { component }\end{array}$ & Percentage & Relative percentage \\
\hline $\begin{array}{c}\text { Sand: Grudzeń Las } \\
0.32 / 0.40 / 0.20\end{array}$ & 92.6 & 100 sand matrix \\
\hline $\begin{array}{c}\text { Sodium water } \\
\text { glass R-145 }\end{array}$ & 6.5 & 7 relative to sand matrix \\
\hline $\begin{array}{c}\text { Ester hardener (of } \\
\text { ethylene glycol dia- } \\
\text { cetate) Flodur FM-4 }\end{array}$ & 0.9 & 14 relative to water glass \\
\hline
\end{tabular}

Preparation of the moulding sand included pre-mixing the sand matrix and water glass R-145 in a Mix-Muller Batch Mixer for 5 minutes, followed by further mixing for $1 \mathrm{~min}$ ute with ester hardener. Standard specimens were made out of the prepared moulding sand for compressive strength tests (a cylindrical specimen $\emptyset=50 \mathrm{~mm}, h=50 \mathrm{~mm}$ ). The specimens were made in the laboratory rammer LUA-2e. Three hours after forming the moulding sand exhibited the mean compressive strength of $R_{m}=2 \mathrm{MPa}$, and after 5 days $R_{m}=5 \mathrm{MPa}$. The die was made out of the prepared moulding sand. The die mounted on the experimental stand is presented in Figure 7.

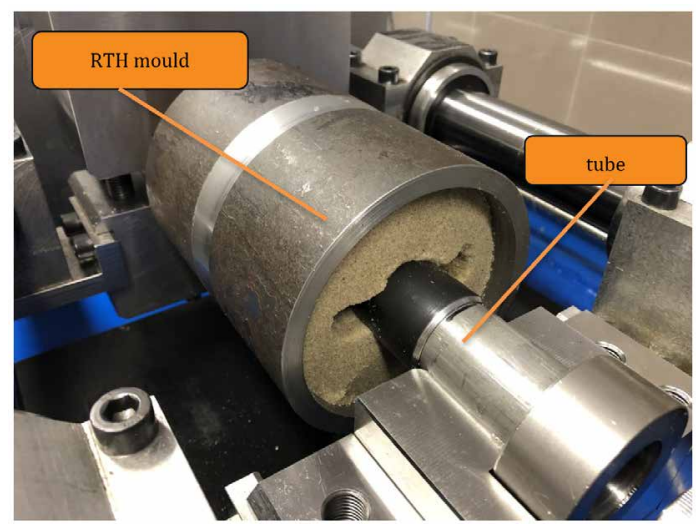

Fig. 7. The test stand with the installed die made of moulding sand with water glass

\section{EXPERIMENTAL RESULTS}

In the case of the alternative geometry, contact between the moulding sand and the profile occurred at a later stage of forming, which made considerable profile deformation possible. Figure 8a shows the profile subjected to forming in the type B die, while Figure $8 \mathrm{~b}$ represents the profile obtained as a result of forming, as well the cross-section geometry in the central part of the profile under forming.

The obtained profile shape clearly demonstrates the influence of the die cavity geometry on the profile under forming. In the process of forming, profile deformation was limited in the area of contact between the profile and the moulding sand, and at the same time the deformation was considerably larger in the area with no contact between the profile and the die cavity. As a result of forming, a profile with the initial circular cross-section of the $38 \mathrm{~mm}$ diameter, what was obtained was a profile with the elliptical cross-section with the major axes of $43 \mathrm{~mm}$ and $53 \mathrm{~mm}$.

As demonstrated in the numerical modelling (Fig. 4a, b), the properties of the moulding sand exert a decisive influence on the area of contact between the profile under forming and the die cavity.

a)

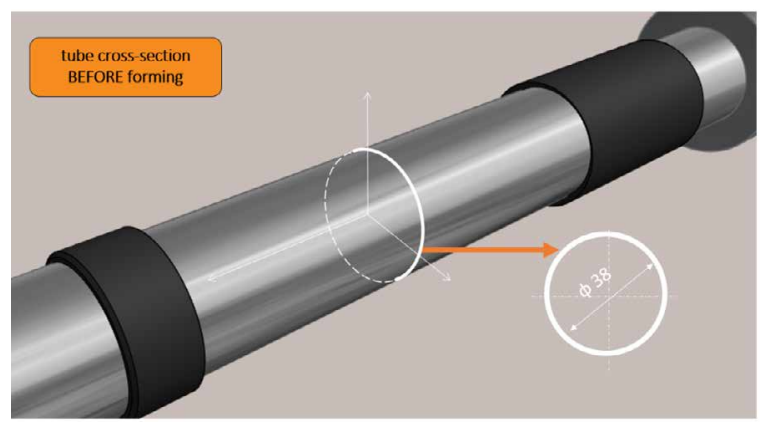

b)

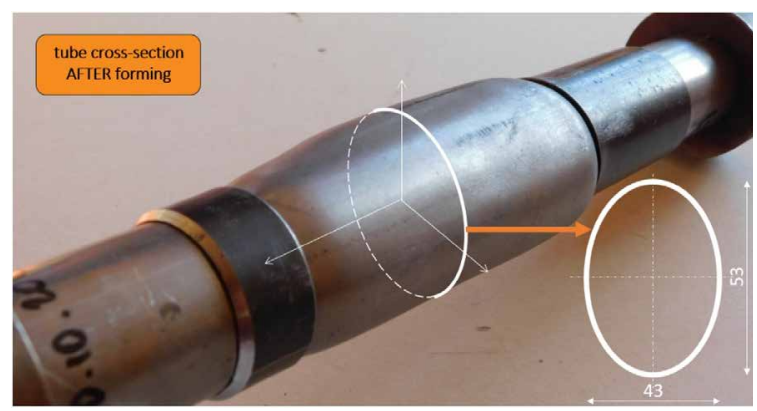

Fig. 8. The dimensions of the cross section of the profile under forming: a) initial geometry - diameter Ø $38 \mathrm{~mm}$; b) after forming elliptical cross-section

\section{SUMMARY}

The initial experimental tests demonstrated the viability of the proposed new method for obtaining diverse profile shapes, including profiles with an elliptical cross-section involving a considerable difference between the two diameters. Numerical modelling demonstrated a considerable 
influence on the profile under forming of such moulding sand parameters as the cohesion coefficient $c$ or the internal friction angle $\phi$.

The possibility of obtaining considerable deformations is directly dependent on the profile material's capability of being displaced into the deformation area. It is worth noting that the stability of the process requires the development of mould compacting methods in the entire volume and it is an important factor in obtaining a commercially repeatable profile shape.

\section{REFERENCES}

[1] Kocańda A. \& Sadłowska H. (2008). Automotive component development by means of hydroforming: A review. Archives of Civil and Mechanical Engineering, 8(3), 55-72. Doi: 10.1016/ S1644-9665(12)60163-0.

[2] Pinto M., Santos A., Teixeira P. \& Bolt P. (2008). Study on the usability and robustness of polymer and wood materials for tooling in sheet metal forming. Journal of Materials Processing Technology, 202(1-3), 47-53. Doi: 10.1016/j.jmatprotec. 2007.08.082.
[3] Kochański A. \& Sadłowska H. (2019). Patent no. PL424401. Sposób hydromechanicznego kształtowania profili cienkościennych i matryca do hydromechanicznego kształtowania profili cienkościennych. Biuletyn Urzędu Patentowego, Urząd Patentowy Rzeczypospolitej Polskiej. Wynalazki i Wzory Użytkowe, 17, 11.

[4] Bast J., Kadauw A. \& Malaschkin A. (2009). Optimising of Moulding Parameters for Green Sand Compaction by Computer Simulation and a New Compaction Measuring Device. International Journal of Metalcasting, 3(2), 55-65.

[5] Waszkiewicz S. (1992). Wpływ błędów odwzorowania wnęki formy na dokładność wymiarową odlewów. Prace Naukowe Politechnika Warszawska. Mechanika, z. 147. Warszawa: Wydawnictwa Politechniki Warszawskiej.

[6] Dodge Woodson R. (2011). Appendix III - Foundry Sand Facts for Civil Engineers. In: Concrete Portable Handbook. Elsevier, 299-372.

[7] Godula T. (1984). Metoda rozpoznawania warunków geologiczno-inżynierskich warstw karbońskich dla potrzeb projektowania kopalń oraz wyniki jej zastosowania w rejonie Bzie-Zebrzydowice [Doctoral Thesis]. Gliwice: Politechnika Śląska.

[8] Sadłowska H. (2016). Strains in free tube hydroforming process. Journal of Manufacturing Technologies, 41(1), 7-11.

[9] Sadłowska H., Jasiński C. \& Morawiński Ł. (2020). Strain measurements on the tube hydroforming testing machine. Archives of Metals and Metallurgy, 65(1), 257-263. 